\title{
The predictive validity for mortality of the driving pressure and the mechanical power of ventilation
}

David M. P. van Meenen ${ }^{1 *}$ (D, Ary Serpa Neto ${ }^{1,2}$, Frederique Paulus ${ }^{1}$, Coen Merkies ${ }^{1}$, Laura R. Schouten ${ }^{1}$, Lieuwe D. Bos ${ }^{1,3}$, Janneke Horn ${ }^{1}$, Nicole P. Juffermans ${ }^{1,3}$, Olaf L. Cremer ${ }^{4}$, Tom van der Poll ${ }^{5,6,7}$, Marcus J. Schultz ${ }^{1,3,8,9}$ and for the MARS Consortium

From 4th International Symposium on Acute Pulmonary Injury and Translational Research - INSPIRES 2019 Dresden, Germany. 25-26 November 2019

\author{
* Correspondence: d.m. \\ vanmeenen@amsterdamumc.nl \\ ${ }^{1}$ Department of Intensive Care, \\ University of Amsterdam, \\ Amsterdam University Medical \\ Centers, Location "Academic \\ Medical Center", Meibergdreeg 9, \\ 1105 AZ Amsterdam, The \\ Netherlands \\ Full list of author information is \\ available at the end of the article
}

\begin{abstract}
Background: Outcome prediction in critically ill patients under invasive ventilation remains extremely challenging. The driving pressure $(\Delta P)$ and the mechanical power of ventilation (MP) are associated with patient-centered outcomes like mortality and duration of ventilation. The objective of this study was to assess the predictive validity for mortality of the $\Delta \mathrm{P}$ and the MP at $24 \mathrm{~h}$ after start of invasive ventilation.
\end{abstract}

Methods: This is a post hoc analysis of an observational study in intensive care unit patients, restricted to critically ill patients receiving invasive ventilation for at least 24 $\mathrm{h}$. The two exposures of interest were the modified $\Delta \mathrm{P}$ and the MP at $24 \mathrm{~h}$ after start of invasive ventilation. The primary outcome was 90 -day mortality; secondary outcomes were ICU and hospital mortality. The predictive validity was measured as incremental 90-day mortality beyond that predicted by the Acute Physiology, Age and Chronic Health Evaluation (APACHE) IV score and the Simplified Acute Physiology Score (SAPS) II.

Results: The analysis included 839 patients with a 90-day mortality of $42 \%$. The median modified $\Delta \mathrm{P}$ at $24 \mathrm{~h}$ was 15 [interquartile range 12 to 19] $\mathrm{cm} \mathrm{H}_{2} \mathrm{O}$; the median MP at $24 \mathrm{~h}$ was 206 [interquartile range 145 to 298] $10^{-3} \mathrm{~J} / \mathrm{min} / \mathrm{kg}$ predicted body weight (PBW). Both parameters were associated with 90-day mortality (odds ratio (OR) for $1 \mathrm{~cm} \mathrm{H}_{2} \mathrm{O}$ increase in the modified $\Delta \mathrm{P}, 1.05$ [95\% confidence interval (CI) 1.03 to 1.08$] ; P<0.001 ;$ OR for $10010^{-3} \mathrm{~J} / \mathrm{min} / \mathrm{kg}$ PBW increase in the MP, 1.20 [95\% Cl 1.09 to 1.33 ]; $P<0.001$ ). Area under the ROC for 90 -day mortality of the modified $\Delta \mathrm{P}$ and the MP were $0.70[95 \% \mathrm{Cl} 0.66$ to 0.74$]$ and $0.69[95 \% \mathrm{Cl} 0.65$ to 0.73], which was neither different from that of the APACHE IV score nor that of the SAPS II.

Conclusions: In adult patients under invasive ventilation, the modified $\Delta \mathrm{P}$ and the $\mathrm{MP}$ at $24 \mathrm{~h}$ are associated with 90 day mortality. Neither the modified $\Delta \mathrm{P}$ nor the MP at $24 \mathrm{~h}$ has predictive validity beyond the APACHE IV score and the SAPS II.

(Continued on next page)

\section{Springer Open}

(C) The Author(s). 2020 Open Access This article is licensed under a Creative Commons Attribution 4.0 International License, which permits use, sharing, adaptation, distribution and reproduction in any medium or format, as long as you give appropriate credit to the original author(s) and the source, provide a link to the Creative Commons licence, and indicate if changes were made. The images or other third party material in this article are included in the article's Creative Commons licence, unless indicated otherwise in a credit line to the material. If material is not included in the article's Creative Commons licence and your intended use is not permitted by statutory regulation or exceeds the permitted use, you will need to obtain permission directly from the copyright holder. To view a copy of this licence, visit http://creativecommons.org/licenses/by/4.0/. 
(Continued from previous page)

Keywords: Intensive care unit, Invasive ventilation, Mortality, Prognostication, Predictive validity, Respiratory system driving pressure, Driving pressure, $\Delta P$, Mechanical power of ventilation, Mechanical power

\section{Introduction}

Outcome prediction in intensive care unit (ICU) patients under invasive ventilation for acute respiratory failure is challenging $[1,2]$. Disease severity scores, like the Acute Physiology, Age and Chronic Health Evaluation (APACHE) IV score, and the Simplified Acute Physiology Score (SAPS) II, are effective in estimating the risk of death in the general ICU population [3, 4]. For ICU patients with acute respiratory distress syndrome (ARDS), the Berlin Definition for ARDS has been proposed for risk of death classification, [5] albeit with limited success [6, 7].

The driving pressure $(\Delta \mathrm{P})$ represents the ratio between tidal volume $\left(V_{T}\right)$ and respiratory system compliance $(C)[8,9]$, and can be calculated as the difference between plateau pressure $\left(P_{\text {plat }}\right)$ and positive end-expiratory pressure (PEEP). The $\Delta \mathrm{P}$ has been shown to be the ventilator parameter associated most strongly with mortality, and is even suggested as a key parameter for optimization when applying invasive ventilation [10-13]. The mechanical power of ventilation (MP) represents the amount of energy per unit of time transferred from the ventilator to the respiratory system and lung tissue [14], and can be calculated as the product of $V_{T}$, respiratory rate $(\mathrm{RR})$, and the difference between the peak pressure $\left(P_{\text {peak }}\right)$ and $0.5 \times \Delta \mathrm{P}[15]$. An independent association between the MP and mortality has been demonstrated in invasively ventilated ICU patients $[16,17]$.

The associations between the $\Delta \mathrm{P}$ and the $\mathrm{MP}$, and mortality make them both attractive for use in risk classification for death. It is unknown, however, whether the $\Delta \mathrm{P}$ and the MP hold prognostic value, and in particular, whether they add to the frequently used and robust APACHE IV score and SAPS II. Therefore, we determined the predictive validity of the $\triangle \mathrm{P}$ and the MP using data stored in the database of the "Molecular diAgnosis and Risk Stratification of sepsis" (MARS) study, an observational study that captured granular data of a cohort of general ICU patients in two Dutch hospitals [18, 19]. It was hypothesized that the $\triangle \mathrm{P}$ and the MP, after initial ventilatory stabilization, are associated with 90day mortality, and have predictive validity beyond the APACHE IV score and the SAPS II.

\section{Methods}

\section{Design and ethical approval}

This was a post hoc analysis of the MARS study that ran from January 2011 to January 2014. The database of the MARS study contains prospectively collected detailed demographic, clinical and outcome data, and detailed ventilator settings, variables, and parameters from a large cohort of ICU patients, not restricted to patients with sepsis but instead patients who were admitted beyond the next calendar day $[18,19]$. The Institutional Review Board approved the protocol of MARS (protocol no. 10-056C) and the use of an opt-out consent procedure, in which participants and their legal representatives were notified of the study in writing. The MARS study was registered at www.clinicaltrials.gov (study identifier NCT01905033). 


\section{Inclusion and exclusion criteria}

Patients were eligible for inclusion in the MARS study if they had an expected length of stay in the ICU of $>24 \mathrm{~h}$. The MARS study itself had no exclusion criteria. For the purpose of the current post hoc analysis, readmitted patients were excluded, as well as patients who never had received invasive ventilation, or had received invasive ventilation for $<24 \mathrm{~h}$. To have reliable calculation of the modified $\Delta \mathrm{P}$ and the $\mathrm{MP}$, patients under pressure support ventilation, and patients in whom there was evidence of spontaneous breathing at $24 \mathrm{~h}$ after start of invasive ventilation were excluded, as were patients of whom we had incomplete data necessary for calculating the modified $\Delta \mathrm{P}$ or the $\mathrm{MP}$ at that time point.

\section{Collection of data and diagnosing ARDS}

In the MARS study, a dedicated team of trained researchers collected baseline characteristics and outcomes and diagnosed ARDS and its severity using the at that time used American-European Consensus Conference definition for ARDS. All patients could be reclassified using the Berlin Definition [20]; patients originally classified as having ARDS with the older definition could be re-classified as having mild, moderate, or severe ARDS with the latest definition.

\section{Calculation of the $\triangle \mathrm{P}$ and the MP}

Ventilation variables, including ventilatory mode, $V_{T}$, set and measured $R R\left(R_{\text {set }}\right.$ and $\left.\mathrm{RR}_{\text {measured }}\right)$, maximum airway pressure $\left(P_{\max }\right)$ at zero flow, PEEP, fraction of inspired oxygen $\left(\mathrm{FiO}_{2}\right)$, and blood gas analysis results were collected at the start of ventilation, after $24 \mathrm{~h}$ and thereafter daily till invasive ventilation was discontinued; measurements were collected for a single breath, and only if the patients was stable, and sufficiently long after certain procedures (like nursing activities, changes in body position, recruitment maneuvers if used). Spontaneous breathing was recognized by comparing $R_{\text {set }}$ and $R R_{\text {measured }}$ i.e., a higher $R R_{\text {measured }}$ than $R R_{\text {set }}$ was seen as evidence of spontaneous breathing.

For calculating the modified $\Delta \mathrm{P}$ and the $\mathrm{MP}$, ventilation variables collected at $24 \mathrm{~h}$ after start of invasive ventilation were used, to guarantee that all patients were sufficiently stabilized, and also because previous studies showed that using ventilation data at that time point had better predictive capacities than those collected shortly after initiation of invasive ventilation [20-23].

The modified $\Delta \mathrm{P}$ was calculated by subtracting PEEP from $P_{\max }[22,24]$.

$$
\Delta \mathrm{P}=\mathrm{P}_{\max }-\mathrm{PEEP}
$$

Absolute MP was calculated using an adjusted power equation [15, 25].

$$
\text { Absolute } \mathrm{MP}=0.098 * \mathrm{~V}_{\mathrm{T}} * \mathrm{RR} *(\operatorname{Pmax}-0.5 * \Delta \mathrm{P})
$$

$P_{\text {peak }}$ is suggested to be used in the originally reported "power equation" [25]. As proposed before $[22,24]$, for the present analysis $P_{\max }$ instead of $P_{\text {peak }}$ was used, as in the participating ICUs pressure-controlled ventilation was exclusively used for assist ventilation.

Predicted body weight (PBW) was calculated by using the equation as used in previous studies of ventilation [26]. 


$$
\begin{aligned}
& \text { PBW }=50+0 \cdot 91 \text { (height }[\mathrm{cm}]-152 \cdot 4) \text { in males } \\
& \text { PBW }=45 \cdot 5+0 \cdot 91 \text { (height }[\mathrm{cm}]-152 \cdot 4 \text { ) in females }
\end{aligned}
$$

The MP was normalized to PBW by dividing the absolute MP by the PBW [16].

$$
\mathrm{MP}=\text { absolute } \mathrm{MP} / \mathrm{PBW}
$$

\section{Outcomes}

The following clinical outcomes were collected: 90-day mortality, ICU and hospital mortality, and duration of ventilation expressed as the number of days ventilator-free and alive at day 28 (VFD-28).

\section{Study endpoint}

The primary study endpoint was the added predictive value of the two ventilation parameters of interest to baseline 90-day mortality prediction based on APACHE IV scores. Secondary endpoints were the odds ratios (ORs) of the two ventilation parameters of interest for 90-day, ICU and hospital mortality, and the effect estimates (EEs) for VFD-28.

\section{Statistical analysis}

Continuous variables were expressed as medians (25th-75th interquartile range [IQR]), and categorical variables as proportions. Continuous variables were analyzed using Mann-Whitney $U$ test for non-normally distributed data or a Welch two-sample $t$ test for normally distributed data, proportions were compared using Fisher exact test.

First, patients were scored based on the modified $\Delta \mathrm{P}$ and the MP calculated at $24 \mathrm{~h}$ after the start of invasive ventilation in the ICU. Based on the median of the modified $\Delta \mathrm{P}$ and the MP, patients were stratified into groups of patients with a low or a high modified $\Delta \mathrm{P}$, and a low or a high $\mathrm{MP}$, respectively. Survival analyses were performed for the four groups using a log-rank test. Then, the ORs for an increase $1 \mathrm{~cm} \mathrm{H}_{2} \mathrm{O}$ in the modified $\Delta \mathrm{P}$, and for an increase in $10010^{-3} \mathrm{~J} / \mathrm{min} / \mathrm{kg} \mathrm{PBW}$ in the MP for 90-day mortality, ICU mortality, and hospital mortality were calculated. The EEs for VFD-28 were also calculated.

For determining the predictive validity of the two ventilatory parameters of interest, the first baseline risk for death was calculated using a generalized linear model in which 90-day mortality was used as outcome and the APACHE IV score or SAPS II as predictor. Thereafter, two separate models were created in which the modified $\Delta \mathrm{P}$ and the MP were added. This data was then used to calculate the area under the receiver operator characteristic curve (AUROC) of in total three models (i.e., the baseline risk, the baseline risk + the modified $\Delta \mathrm{P}$, and the baseline risk + the MP).

One sensitivity analysis was performed, in which the interaction between the predictive validity of the $\triangle \mathrm{P}$ or the MP for 90-day mortality and presence of ARDS was determined. As a post hoc analysis, we calculated the AUROC of an additional model containing both modified $\triangle \mathrm{P}$ and $\mathrm{MP}$.

Statistical analyses were performed using $\mathrm{R}$ and the $\mathrm{R}$-Studio interface $(\mathrm{R}$ version 3.3.3., www.r-project.org, Vienna, Austria, retrieved January 2017). A $P$ value $<0.05$ was considered as statistically significant. 


\section{Results}

Patients

Consort diagram is given in Fig. 1. Of the 8303 enrollments in the MARS study, 3562 $(43 \%)$ patients were under invasive ventilation for $>24 \mathrm{~h}$. After excluding ineligible patients, a total of 839 patients were selected for the current analysis. Baseline demographics, major outcome data and ventilation settings, variables, and parameters are presented in Table 1. Baseline characteristics of patients with a low versus a high modified $\Delta \mathrm{P}$, and a low versus a high MP are presented in Table 1. All-cause 90-day mortality was $42 \%$. Survivors and non-survivors differed in age, risk of death based on the APACHE IV score, presence of chronic kidney failure, blood pressure, body temperature, and sequential organ failure assessment (SOFA) scores. Non-survivors had less VFD-28, a shorter hospital length of stay (LOS), and higher ICU and hospital mortality rates. $\mathrm{FiO}_{2}$ and $\mathrm{PEEP}$ were similar between survivors and non-survivors; $P_{\max }$ was lower, and $\mathrm{pHa}$ and arterial $\mathrm{HCO}_{3}{ }^{-}$levels were higher in survivors compared to non-survivors.

\section{The $\Delta \mathrm{P}$ and the MP in survivors and non-survivors}

The median modified $\Delta \mathrm{P}$ was 15 [12 to 19] $\mathrm{cm} \mathrm{H}_{2} \mathrm{O}$; the median MP was 206 [145 to 298] $10^{-3} \mathrm{~J} / \mathrm{min} / \mathrm{kg}$ PBW. Based on these, 441 patients were stratified to a low modified $\Delta \mathrm{P}$ group, and 398 were stratified to the high modified $\Delta \mathrm{P}$ group; the low $\mathrm{MP}$ group consisted of 429 patients, and the high MP group of 410 patients. The modified $\Delta \mathrm{P}$ and

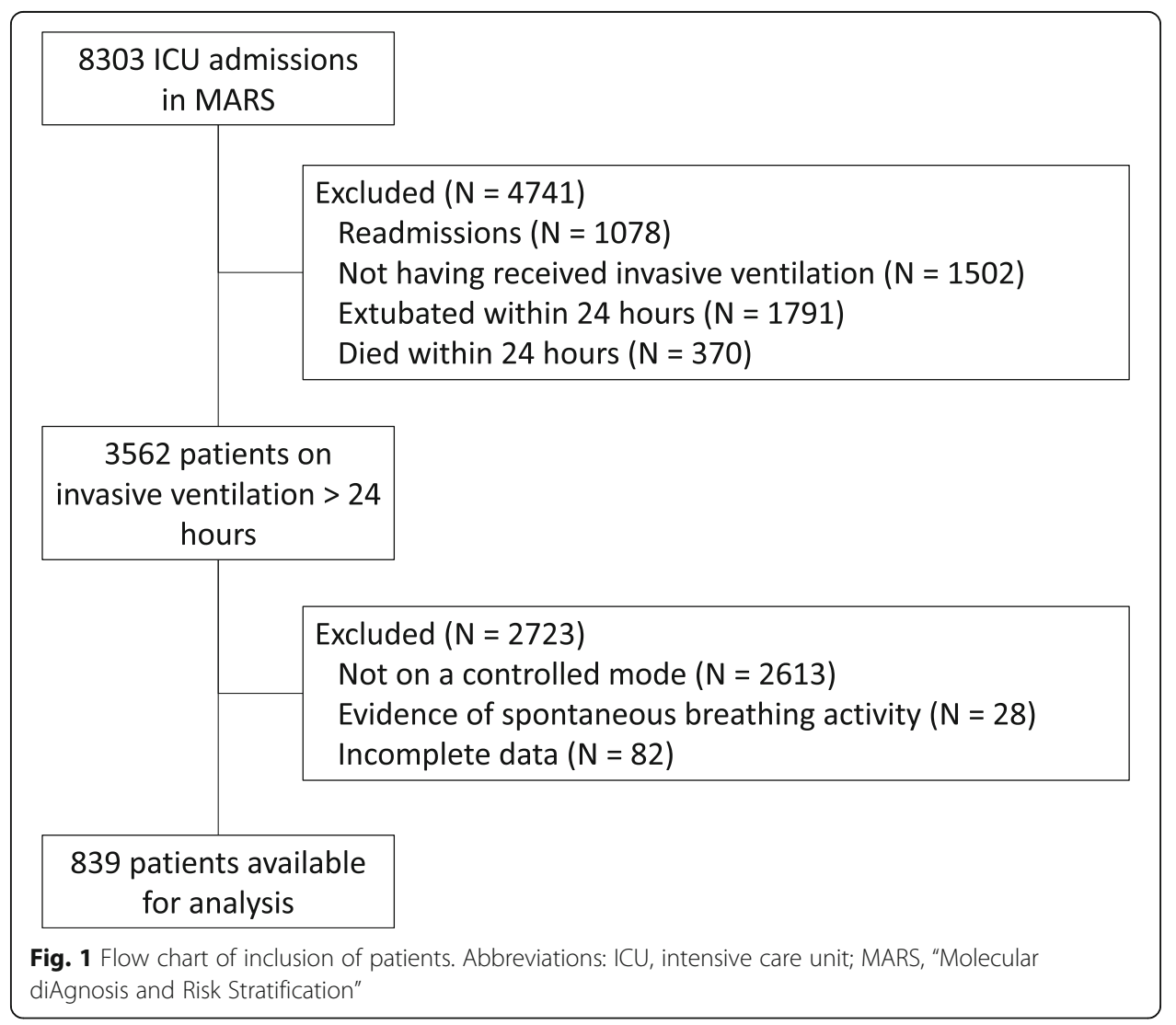


Table 1 Patient characteristics, outcomes, and ventilation characteristics

\begin{tabular}{|c|c|c|c|c|}
\hline \multirow[t]{2}{*}{ Characteristics } & All & Survivors & Non-survivors & \multirow{2}{*}{$\begin{array}{l}P \\
\text { value }\end{array}$} \\
\hline & $\boldsymbol{N}=839$ & $\boldsymbol{N}=489$ & $\boldsymbol{N}=350$ & \\
\hline Age (years) & 61 [50 to 70$]$ & 58 [47 to 68$]$ & 63 [53 to 73$]$ & $<0.001$ \\
\hline Gender (male) & $555(66 \%)$ & 314 (64\%) & 241 (69\%) & 0.23 \\
\hline \multicolumn{2}{|l|}{ Ethnicity, no. (\%) } & & & 0.09 \\
\hline African & $12(1 \%)$ & $5(1 \%)$ & $7(2 \%)$ & \\
\hline Asian & $9(1 \%)$ & $4(1 \%)$ & $5(1 \%)$ & \\
\hline Caucasian & 733 (87\%) & $428(88 \%)$ & 305 (87\%) & \\
\hline Latin American & $16(2 \%)$ & $8(2 \%)$ & $8(2 \%)$ & \\
\hline Other & $69(8 \%)$ & $44(9 \%)$ & $25(7 \%)$ & \\
\hline BMI $\left(\mathrm{kg} / \mathrm{m}^{2}\right)$ & 25 [23 to 29] & 25 [23 to 29] & 25 [23 to 28$]$ & 0.61 \\
\hline PBW (kg) & 71 [62 to 75$]$ & 71 [62 to 75$]$ & 71 [62 to 75$]$ & 0.66 \\
\hline ARDS, N (\%) & $223(22 \%)$ & 130 (21\%) & $93(22 \%)$ & 0.96 \\
\hline Mild & 118 (14\%) & $67(14 \%)$ & $51(14 \%)$ & \\
\hline Moderate & 97 (12\%) & $60(13 \%)$ & $37(10 \%)$ & \\
\hline Severe & $8(1 \%)$ & $3(1 \%)$ & $5(1 \%)$ & \\
\hline \multicolumn{2}{|l|}{ Reason for ICU admission, no. (\%) } & & & 0.25 \\
\hline Planned surgery & $116(14 \%)$ & $75(15 \%)$ & $41(12 \%)$ & \\
\hline Emergency surgery & $207(25 \%)$ & $122(25 \%)$ & $85(24 \%)$ & \\
\hline Medical & $513(61 \%)$ & $289(59 \%)$ & $224(64 \%)$ & \\
\hline Risk of death $(\%)^{a}$ & 32 [14 to 59$]$ & 23 [10 to 47$]$ & 48 [23 to 74$]$ & $<0.001$ \\
\hline \multicolumn{2}{|l|}{ Reason for intubation, no. (\%) } & & & 0.06 \\
\hline Cardiac arrest & $134(16 \%)$ & $58(12 \%)$ & $76(22 \%)$ & \\
\hline Post-surgery & $207(25 \%)$ & $130(27 \%)$ & 77 (22\%) & \\
\hline Depressed level of consciousness & $77(9 \%)$ & $45(9 \%)$ & $32(9 \%)$ & \\
\hline Respiratory failure & $312(37 \%)$ & $187(38 \%)$ & $125(36 \%)$ & \\
\hline Other & 109 (13\%) & 69 (14\%) & $40(11 \%)$ & \\
\hline \multicolumn{5}{|l|}{ Chronic comorbidity, no. (\%) } \\
\hline Hypertension & $231(28 \%)$ & $137(28 \%)$ & $94(27 \%)$ & 0.73 \\
\hline Diabetes mellitus & $127(15 \%)$ & $69(14 \%)$ & $58(17 \%)$ & 0.40 \\
\hline Heart failure & $69(8 \%)$ & $44(9 \%)$ & $25(5 \%)$ & 0.39 \\
\hline Chronic kidney failure & $60(7 \%)$ & $19(4 \%)$ & $41(12 \%)$ & $<0.001$ \\
\hline Cirrhosis & $9(1 \%)$ & $1(0 \%)$ & $8(2 \%)$ & 0.01 \\
\hline COPD & $89(11 \%)$ & $43(9 \%)$ & $46(13 \%)$ & 0.06 \\
\hline Oxygen at home & $5(1 \%)$ & $2(0 \%)$ & $3(1 \%)$ & 0.72 \\
\hline Cancer & $46(5 \%)$ & $19(4 \%)$ & $27(8 \%)$ & 0.43 \\
\hline Immunodeficiency & $88(10 \%)$ & $47(10 \%)$ & $41(12 \%)$ & 0.40 \\
\hline Ventilation at home & $10(1 \%)$ & $6(1 \%)$ & $4(1 \%)$ & 1.00 \\
\hline \multicolumn{5}{|l|}{ Vital signs } \\
\hline $\mathrm{SpO}_{2}(\%)$ & 98 [96 to 100] & 98 [96 to 100] & 98 [96 to 100] & 0.79 \\
\hline Heart rate (bpm) & 101 [83 to 120$]$ & $100[83$ to 118$]$ & $102[83$ to 121$]$ & 0.39 \\
\hline MAP $(\mathrm{mm} \mathrm{Hg})$ & 57 [52 to 62$]$ & 58 [53 to 63$]$ & $56[50$ to 60$]$ & $<0.001$ \\
\hline Temperature $(\mathrm{C})$ & 36.7 [35.9 to 37.3] & $36.8[36.0$ to 37.4$]$ & $36.6[35.7$ to 37.2$]$ & 0.03 \\
\hline \multicolumn{5}{|l|}{ Severity of illness, SOFA score } \\
\hline Total & $5[4$ to 8$]$ & $4[3$ to 7$]$ & $6[4$ to 9$]$ & $<0.001$ \\
\hline
\end{tabular}


Table 1 Patient characteristics, outcomes, and ventilation characteristics (Continued)

\begin{tabular}{|c|c|c|c|c|}
\hline \multirow[t]{2}{*}{ Characteristics } & \multirow{2}{*}{$\begin{array}{l}\text { All } \\
\boldsymbol{N}=839\end{array}$} & \multirow{2}{*}{$\begin{array}{l}\text { Survivors } \\
\boldsymbol{N}=489\end{array}$} & \multirow{2}{*}{$\begin{array}{l}\text { Non-survivors } \\
\boldsymbol{N}=350\end{array}$} & \multirow{2}{*}{$\begin{array}{l}P \\
\text { value }\end{array}$} \\
\hline & & & & \\
\hline Non-pulmonary SOFA & $4[4$ to 7$]$ & $4[3$ to 6$]$ & $5[4$ to 8$]$ & $<0.001$ \\
\hline Pulmonary & $0[0$ to 1$]$ & $0[0$ to 1$]$ & $0[0$ to 1$]$ & 0.07 \\
\hline Hematologic & $0[0$ to 1$]$ & $0[0$ to 1$]$ & $0[0$ to 2$]$ & 0.12 \\
\hline Liver & $0[0$ to 0$]$ & $0[0$ to 0$]$ & $0[0$ to 0$]$ & 0.12 \\
\hline Circulation & $4[3$ to 4$]$ & $3[2$ to 4$]$ & $4[3$ to 4$]$ & $<0.001$ \\
\hline Neurology & $0[0$ to 1$]$ & $0[0$ to 1$]$ & $0[0$ to 3$]$ & 0.01 \\
\hline Renal & $0[0$ to 0$]$ & $0[0$ to 0$]$ & $0[0$ to 1$]$ & $<0.001$ \\
\hline \multicolumn{5}{|l|}{ Outcomes } \\
\hline ICU mortality, no. (\%) & $220(26 \%)$ & $0(0 \%)$ & $220(63 \%)$ & $<0.001$ \\
\hline Hospital mortality, no. (\%) & $305(36 \%)$ & $3(1 \%)$ & $301(86 \%)$ & $<0.001$ \\
\hline ICU LOS, days & $7[4$ to 12$]$ & 7 [4 to 13$]$ & 7 [4 to 12$]$ & 0.12 \\
\hline Hospital LOS, days & $22[11$ to 42$]$ & 31 [17 to 50] & 13 [6 to 27$]$ & $<0.001$ \\
\hline Duration of mechanical ventilation, days & $5[3$ to 10$]$ & $5[3$ to 10$]$ & $6[3$ to 10$]$ & 0.60 \\
\hline VFD-28, days & $17[0$ to 24$]$ & 23 [18 to 25$]$ & $0[0$ to 0$]$ & $<0.001$ \\
\hline \multicolumn{5}{|l|}{ Ventilatory variables, median [IQR] } \\
\hline Tidal volume (ml) & $471[410$ to 540$]$ & $476[417$ to 546$]$ & $461[405$ to 531$]$ & 0.04 \\
\hline Tidal volume (ml/kg PBW) & $6.8[6.0$ to 8.0$]$ & $6.9[6.1$ to 7.9$]$ & $6.8[5.8$ to 7.9$]$ & 0.09 \\
\hline Respiratory rate (bpm) & $20[16$ to 26$]$ & 20 [15 to 25$]$ & $22[17$ to 28$]$ & 0.003 \\
\hline $\mathrm{FiO}_{2}(\%)$ & $40[40$ to 48$]$ & $40[40$ to 45$]$ & $40[40$ to 50$]$ & 0.27 \\
\hline $\mathrm{P}_{\max }\left(\mathrm{cm} \mathrm{H} \mathrm{H}_{2} \mathrm{O}\right)$ & 23 [18 to 28$]$ & 22 [18 to 27] & 24 [19 to 30$]$ & $<0.001$ \\
\hline PEEP $\left(\mathrm{cm} \mathrm{H}_{2} \mathrm{O}\right)$ & $7[5$ to 10$]$ & $7[5$ to 10$]$ & $8[5$ to 10$]$ & 0.22 \\
\hline Dynamic compliance $\left(\mathrm{ml} / \mathrm{cm} \mathrm{H}_{2} \mathrm{O}\right)$ & $31[23$ to 41$]$ & 32 [25 to 43$]$ & 29 [22 to 37$]$ & $<0.001$ \\
\hline$\Delta \mathrm{P}\left(\mathrm{cm} \mathrm{H}_{2} \mathrm{O}\right)$ & 15 [12 to 19$]$ & 15 [12 to 18$]$ & 16 [13 to 20] & $<0.001$ \\
\hline $\mathrm{MP}\left(10^{-3} \mathrm{~J} / \mathrm{min} / \mathrm{kg}\right.$ PBW $)$ & 206 [145 to 298] & 194 [136 to 280$]$ & 218 [156 to 339] & $<0.001$ \\
\hline \multicolumn{5}{|l|}{ Blood gas analysis results, median [IQR] } \\
\hline $\mathrm{PaO}_{2}(\mathrm{~mm} \mathrm{Hg})$ & $91[77$ to 110$]$ & $91[77$ to 109$]$ & $92[78$ to 112$]$ & 0.68 \\
\hline $\mathrm{PaCO}_{2}(\mathrm{~mm} \mathrm{Hg})$ & 37 [41 to 43$]$ & 38 [32 to 43] & 37 [31 to 43$]$ & 0.53 \\
\hline $\mathrm{pHa}$ & 7.38 [7.33 to 7.44$]$ & $7.39[7.35$ to 7.44$]$ & 7.38 [7.32 to 7.43$]$ & $<0.001$ \\
\hline Bicarbonate $(\mathrm{mmol} / \mathrm{l})$ & 23 [20 to 27] & 24 [21 to 27] & 22 [19 to 26$]$ & $<0.001$ \\
\hline
\end{tabular}

Abbreviations: $\triangle P$ respiratory system driving pressure, $A R D S$ acute respiratory distress syndrome, $B M I$ body mass index, COPD chronic obstructive pulmonary disease, $\mathrm{FiO}_{2}$ fraction of inspired oxygen, $\mathrm{ICU}$ intensive care unit, MAP mean arterial pressure, MP mechanical power of ventilation normalized for predicted bodyweight, $\mathrm{PaCO}_{2}$ arterial carbon dioxide tension, $\mathrm{PaO}_{2}$ arterial oxygen tension, $P B W$ predicted body weight, $P E E P$ positive end-expiratory pressure, $P_{\max }$ maximum airway pressure; SOFA sepsis-related organ failure assessment score, $\mathrm{SpO}_{2}$ peripheral pulse oximetry, LOS length of stay, VFD-28 days ventilator-free and alive

${ }^{a}$ Risk of death is based on the APACHE IV score

the MP were significantly lower in survivors than in non-survivors (Table 1). KaplanMeier curves for the patients with a low or high modified $\Delta \mathrm{P}$, and a low or high MP are shown in Fig. 2.

\section{ORs for major outcomes}

The OR for 90-day mortality for an increase of $1 \mathrm{~cm} \mathrm{H}_{2} \mathrm{O}$ in the modified $\Delta \mathrm{P}$ was 1.05 [95\% confidence interval (CI) 1.03 to 1.08 ]; $P<0.001$; the OR for 90 -day mortality for 


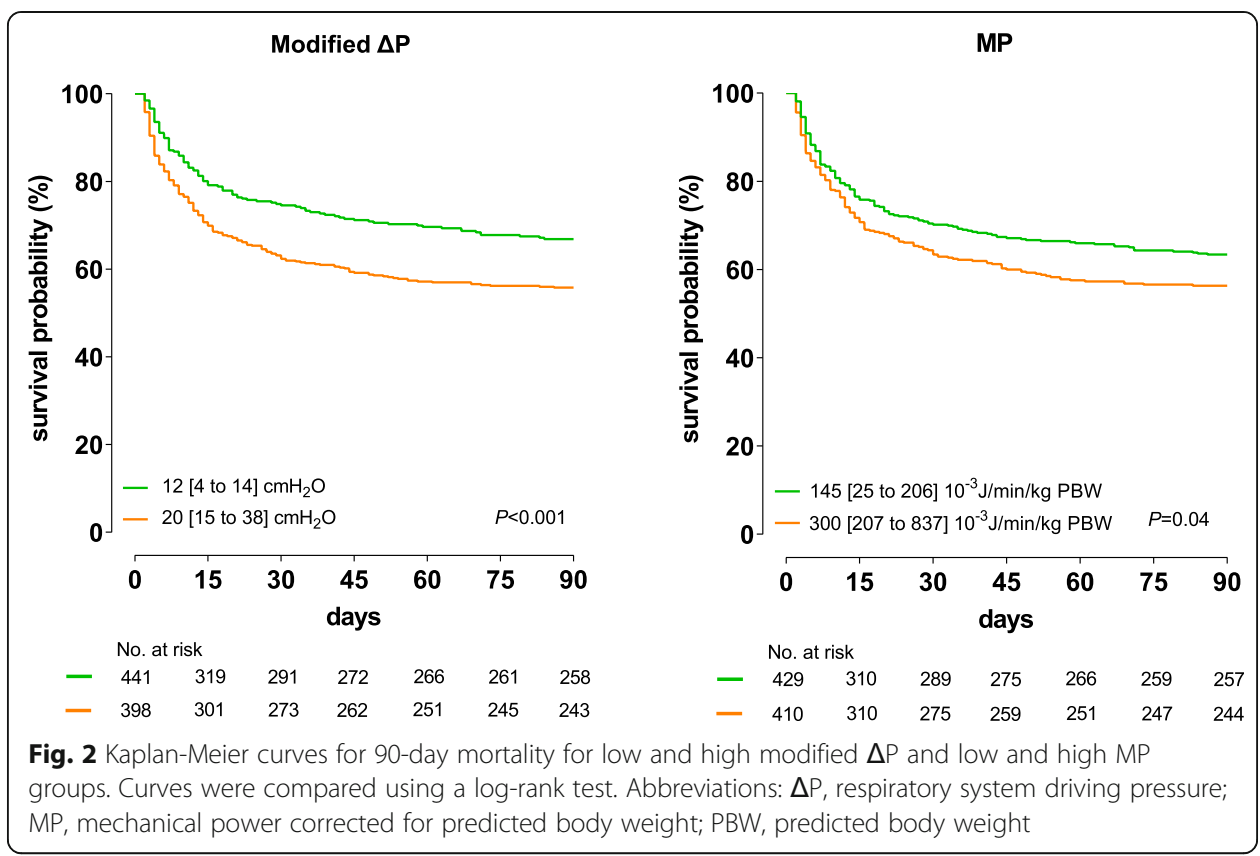

an increase of $10010^{-3} \mathrm{~J} / \mathrm{min} / \mathrm{kg} \mathrm{PBW}$ in the MP was 1.20 [95\% CI 1.09 to 1.33 ]; $P<$ 0.001 .

For ICU mortality, ORs were (modified $\Delta \mathrm{P}$ ) 1.10 [95\% CI 1.07 to 1.13 ]; $P<0.001$ and (MP) 1.35 [95\% CI 1.21 to 1.51 ]; $P<0.001$. For hospital mortality, ORs were (modified $\triangle \mathrm{P}) 1.07$ [95\% CI 1.04 to 1.10 ]; $P<0.001$ and (MP) 1.26 [95\% CI 1.14 to 1.41$] ; P<$ 0.001. The EE for VFDs for $1 \mathrm{~cm} \mathrm{H}_{2} \mathrm{O}$ increase were (modified $\Delta \mathrm{P}$ ) -0.4 [95\% CI -0.6 to -0.3 ]; $P<0.001$ and (MP) -1.6 [95\% CI -2.2 to -1.0$] ; P<0.001$.

\section{Predictive validity}

Discrimination did not improve risk of death classification when adding the modified $\triangle \mathrm{P}$ or the MP to the APACHE IV score. Discrimination did also not improve risk of death classification when adding the modified $\triangle \mathrm{P}$ or the MP to the SAPS II (Fig. 3). Furthermore, discrimination for death did not improve when adding the combination of modified $\triangle \mathrm{P}$ and MP to APACHE IV score or the SAPS II.

\section{Sensitivity analyses}

There was no significant interaction between the predictive validity of the modified $\Delta \mathrm{P}$ $(P=0.10)$ and the MP $(P=0.83)$ for 90 -day mortality, and the presence of ARDS, meaning that the presence of ARDS did not affect the poor predictive validity of the modified $\Delta \mathrm{P}$ and the MP found for the whole cohort.

\section{Discussion}

The results of this post hoc analysis of a large cohort of ICU patients under controlled invasive ventilation for $>24 \mathrm{~h}$ for acute respiratory failure can be summarized as follows: (1) classification of patients into groups based on high or low modified $\Delta \mathrm{P}$ and $\mathrm{MP}$ at $24 \mathrm{~h}$ after start of invasive ventilation results in groups with a difference in risk 


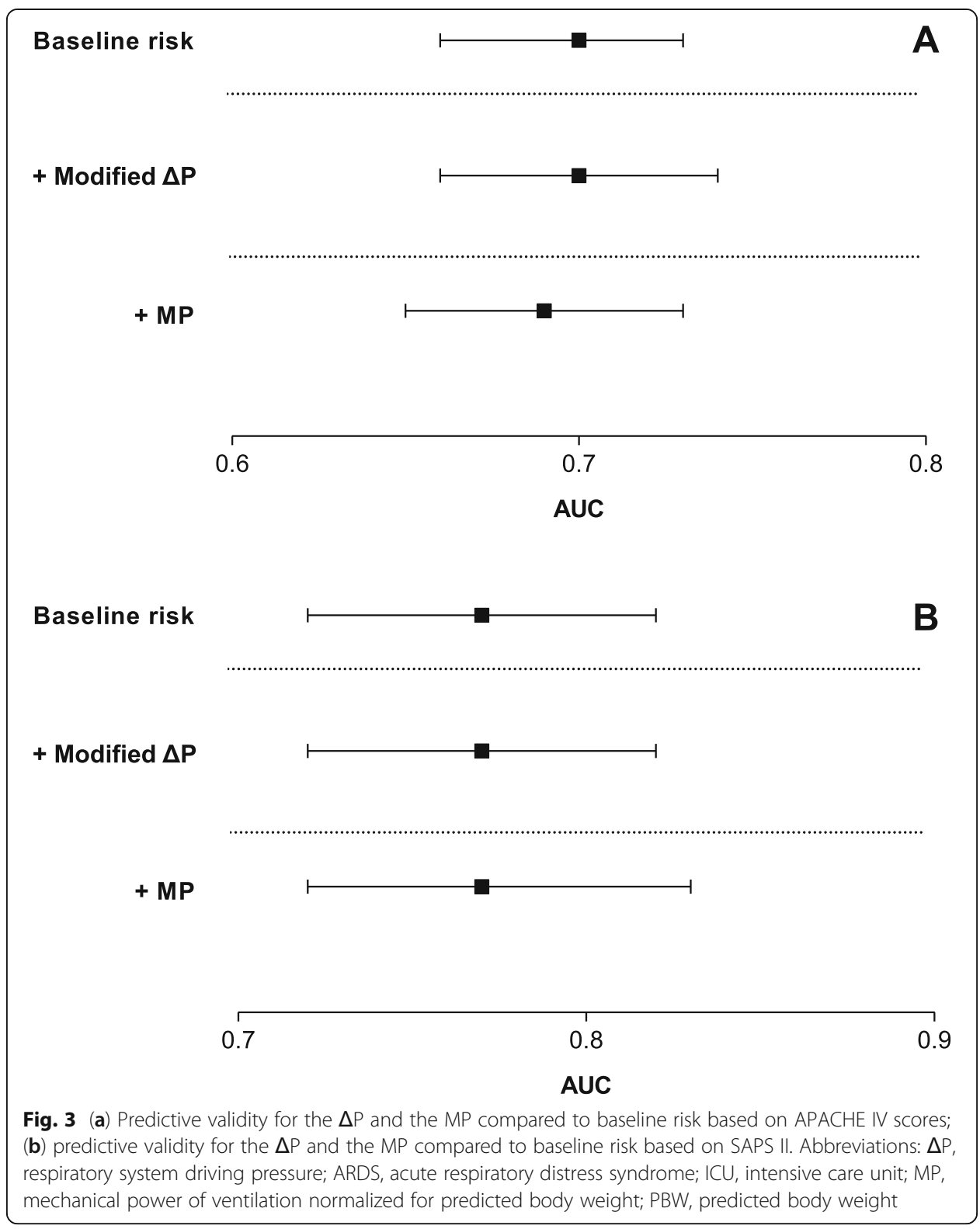

for 90-day mortality, (2) discrimination using the APACHE IV score or SAPS II for 90day mortality does not improve by adding the modified $\triangle \mathrm{P}$ or the MP, and (3) there is no significant interaction between the predictive validity of the modified $\Delta \mathrm{P}$ or the MP and the presence of ARDS. While predicting outcomes of patients who are under invasive ventilation for $>24 \mathrm{~h}$ has the potential to facilitate identification of patients that may benefit from specific management strategies or closer monitoring as well as optimizing the selection of inclusion criteria in future studies, the current findings argue against using the modified $\Delta \mathrm{P}$ or the MP for that purpose.

The strengths of this study are the use of prospectively collected ventilation and outcome data that were captured by a team of dedicated researchers who were trained to use only ventilator settings and ventilator parameters in stable situations. Furthermore, as patients who had or may have had spontaneous breathing activity were excluded, reliable calculations of the modified $\Delta \mathrm{P}$ and the MP could be used. The data and 
outcome assessors were also trained in using strict diagnostic criteria and confirmed outcome data. Also, in MARS patients were enrolled over a relatively short period, minimizing the influence of changes in clinical practice. MARS itself had no exclusion criteria, increasing the generalizability of the findings of the current study. Finally, the number of patients who were excluded because of missing data was minimal.

Parameters focusing on lung mechanics, such as the $\Delta \mathrm{P}$ and the MP, are receiving increasing interest. The modified $\Delta \mathrm{P}$ is associated with outcome and is even suggested to be the only ventilatory parameter that is independently associated with outcome [9-13]. The finding of the current analysis that classification using a high or low modified $\Delta \mathrm{P}$ results in groups with a clear difference in mortality rates; however, this did not translate into improved discrimination for clinically relevant outcomes. The results of classification using the MP are also in line with the results of a recent meta-analysis in patients with ARDS, were having a high MP was associated with higher mortality [16]. However, also the MP had no predictive validity for the clinical outcomes used in this analysis.

Several limitations should be acknowledged. This was a post hoc analysis, performed in a selected subgroup of patients because of the strict inclusion of patients who still received controlled invasive ventilation at $24 \mathrm{~h}$ of ventilation. Because patients in here analyzed cohort were exclusively receiving pressure-controlled ventilation, the calculation of the modified $\Delta \mathrm{P}$ had to be adapted, i.e., $P_{\max }$ was used instead of $P_{\text {peak }}$, as with pressure-controlled ventilation there is no $P_{\text {peak }}$. Of note, $P_{\max }$ was measured and reported at zero flow in patients without a spontaneous breathing effort [22, 24]. Furthermore, and for the same reasons, also the "power equation" was adapted. Also, excluding patients in whom $R R_{\text {set }}$ was lower than $R R_{\text {measured }}$ could have led to exclusion of patients with auto triggering. Finally, the use of set PEEP instead of measured PEEP for the calculation of the $\triangle \mathrm{P}$ could have led to an overestimation of the $\Delta \mathrm{P}$. Therefore, we refer to the modified $\Delta \mathrm{P}$ instead of $\Delta \mathrm{P}$.

\section{Conclusion}

In this conveniently sized cohort of ICU patients under invasive ventilation for $>24 \mathrm{~h}$, 90-day mortality as well as other clinical outcomes differed between patients with low or high modified $\Delta \mathrm{P}$ and MP. The modified $\Delta \mathrm{P}$ and the MP at $24 \mathrm{~h}$ after the start of invasive ventilation, however, had poor predictive validity, there was no interaction for patients with and without ARDS.

\footnotetext{
Abbreviations

$\triangle P$ : Driving pressure; APACHE: Acute Physiology, Age and Chronic Health Evaluation; ARDS: Acute respiratory distress syndrome; AUROC: Area under the receiver operator characteristic curve; BMI: Body mass index; C: Respiratory system compliance; COPD: Chronic obstructive pulmonary disease; Cl: Confidence interval; EE: Effect estimate; Eq: Equation; $\mathrm{FiO}_{2}$ : Fraction of inspired oxygen; ICU: Intensive care unit; LOS: Length of stay; MARS: Molecular diagnosis and risk stratification of sepsis; MP: Mechanical power normalized for predicted body weight; OR: Odds ratio; $\mathrm{PaCO}_{2}$ : Arterial carbon dioxide tension; $\mathrm{PaO}_{2}$ : Arterial oxygen tension; PBW: Predicted body weight; PEEP: Positive end-expiratory pressure; $P_{\text {max }}$ : Maximum airway pressure; $P_{\text {peak }}$ : Peak pressure; $P_{\text {plat }}:$ Plateau pressure; RR: Respiratory rate; $R R_{\text {measured: }}$ Measured respiratory rate; $R_{\text {set }}$ : Set respiratory rate; SAPS: Simplified Acute Physiology Score; $\mathrm{SpO}_{2}$ : Peripheral pulse oximetry; SOFA: Sepsis-related organ failure assessment score; VFD-28: Days ventilator-free and alive; $V_{T}$ : Tidal volume
} 
Amsterdam, The Netherlands); Marc J. Bonten, Olaf L. Cremer, Jos F. Frencken, Kirsten van de Groep, Peter M. Klein Klouwenberg, Maria E. Koster-Brouwer, David S. Ong, Meri R. Varkila and Diana M. Verboom (University Medical Center Utrecht, Utrecht, The Netherlands).

\section{About this supplement}

This article has been published as part of Intensive Care Medicine Experimental Volume 8 Supplement 1, 2020: Proceedings from the Fourth International Symposium on Acute Pulmonary Injury and Translation Research (INSPIRES IV). The full contents of the supplement are available at https://icm-experimental.springeropen.com/articles/ supplements/volume-8-supplement-1.

\section{Authors' contributions}

DMM and MJS designed this study. DMM, CM, LRS, and LDB acquired the data. JH, NPJ, OLC, TP, and MJS supervised the acquisition of the data. DMM and ASN analyzed the data. DMM, ASN, FP, and MJS interpreted the data. DMM and MJS drafted the paper. All authors critically revised the paper. All authors have approved the submitted version and agree both to be personally accountable for their own contribution.

\section{Funding}

This work and publication costs were funded by the "Center for Translational Molecular Medicine" (www.ctmm.nl) with grant 041-201.

\section{Availability of data and materials}

The datasets used and/or analyzed during the current study are available from the corresponding author on reasonable request.

\section{Ethics approval and consent to participate}

The Institutional Review Board approved the protocol of MARS (protocol no. 10-056C) and the use of an opt-out consent procedure, in which participants and their legal representatives were notified of the study in writing.

\section{Consent for publication}

Not applicable.

\section{Competing interests}

The authors declare that they have no competing interests.

\section{Author details}

'Department of Intensive Care, University of Amsterdam, Amsterdam University Medical Centers, Location "Academic Medical Center", Meibergdreeg 9, 1105 AZ Amsterdam, The Netherlands. 'Department of Critical Care Medicine, Hospital Israelita Albert Einstein, Av. Albert Einstein, 627 - Morumbi, São Paulo, Brazil. ${ }^{3}$ Laboratory of Experimental Intensive Care and Anesthesiology (L.E.I.C.A), University of Amsterdam, Amsterdam University Medical Centers, Location "Academic Medical Center", Meibergdreeg 9, 1105 AZ Amsterdam, The Netherlands. "Department of Intensive Care Medicine, University Medical Center Utrecht, Heidelberglaan 100, 3584 CX Utrecht, The Netherlands. ${ }^{5}$ Center for Experimental and Molecular Medicine (CEMM), University of Amsterdam, Amsterdam University Medical Centers, Location "Academic Medical Center", Meibergdreeg 9, 1105 AZ Amsterdam, The Netherlands. ${ }^{6}$ Center for Infection and Immunity Amsterdam, University of Amsterdam, Amsterdam University Medical Centers, Location "Academic Medical Center", Meibergdreeg 9, 1105 AZ Amsterdam, The Netherlands. "Division of Infectious Diseases, University of Amsterdam, Amsterdam University Medical Centers, Location "Academic Medical Center", Meibergdreeg 9, 1105 AZ Amsterdam, The Netherlands. ${ }^{8}$ Mahidol-Oxford Tropical Medicine Research Unit (MORU), Mahidol University, 999 Phutthamonthon Sai 4 Rd, Bangkok, Thailand. ${ }^{9}$ Nuffield Department of Medicine, University of Oxford, Oxford OX1 2JD, UK.

Received: 14 July 2020 Accepted: 16 July 2020

Published: 18 December 2020

\section{References}

1. Sweeney RM, McAuley DF (2016) Acute respiratory distress syndrome. Lancet 388:2416-2430. https://doi.org/10.1016/ S0140-6736(16)00578-X

2. Balzer F, Menk M, Ziegler J, Pille C, Wernecke K, Spies C, Schmidt M, Weber-Carstens S, Deja M (2016) Predictors of survival in critically ill patients with acute respiratory distress syndrome (ARDS): an observational study. BMC Anesthesiol 16:108. https://doi.org/10.1186/s12871-016-0272-4

3. Zimmerman JE, Kramer AA, McNair DS, Malila FM (2006) Acute Physiology and Chronic Health Evaluation (APACHE) IV: hospital mortality assessment for today's critically ill patients. Crit Care Med 34:1297-1310

4. Le Gall JR, Lemeshow S, Saulnier F (1991) A new Simplified Acute Physiology Score (SAPS II) based on a European/ North American multicenter study. JAMA 4:1957-1963

5. The ARDS Definition Task Force (2012) Acute respiratory distress syndrome: the Berlin definition. JAMA 307:2526-2533. https://doi.org/10.1001/jama.2012.5669

6. Bersten AD (2002) Incidence and mortality of acute lung injury and the acute respiratory distress syndrome in three Australian States. Am J Resp Crit Care Med 165(4):443-448. https://doi.org/10.1164/ajrccm.165.4.2101124

7. Seeley E, McAuley DF, Eisner M, Miletin M, Matthay MA, Kallet RH (2008) Predictors of mortality in acute lung injury during the era of lung protective ventilation. Thorax 63(11):994-998. https://doi.org/10.1136/thx.2007.093658 
8. Amato MB, Barbas CS, Medeiros DM, Magaldi RB, Paula Pinto Schettino G, Lorenzi-Filho G, Kairalla RA, Deheinzelin D, Munoz C, Oliveira R, Takagaki TY, Carvalho CR (1998) Effect of a protective-ventilation strategy on mortality in the acute respiratory distress syndrome. N Engl J Med 338:347-354. https://doi.org/10.1056/NEJM199802053380602

9. Estenssoro E, Dubin A, Laffaire E, Canales H, Saenz G, Moseinco M, Pozo M, Gomez A, Baredes N, Jannello G, Osatnik J (2002) Incidence, clinical course, and outcome in 217 patients with acute respiratory distress syndrome. Critical Care Medicine 30:2450-2456. https://doi.org/10.1097/00003246-200211000-00008

10. Bellani G, Laffey JG, Pham T, Fan E, Brochard L, Esteban A, Gattinoni L, van Haren F, Larsson A, DF MA, Ranieri M, Rubenfeld F, Thompson BT, Wrigge H, Slutsky A, Pesenti A, for the LUNG SAFE Investigators and the ESICM Trials Group (2016) Epidemiology, patterns of care, and mortality for patients with acute respiratory distress syndrome in intensive care units in 50 countries. JAMA 315:788-800. https://doi.org/10.1001/jama.2016.0291

11. Amato MBP, Meade MO, Slutsky AS, Brochard L, Costa EL, Schoenfeld DA, Stewart TE, Briel M, Talmor D, Mercat A Richard JM, Carvalho CR, Brower R (2015) Driving pressure and survival in the acute respiratory distress syndrome. N Engl J Med 372:747-755. https://doi.org/10.1056/NEJMsa1410639

12. Neto AS, Hemmes SN, Barbas CS, Beiderlinden M, Fernandez-Bustamante A, Futier E, Gajic O, El-Tahan MR, Ghamdi AA, Günay E, Jaber S, Kokulu S, Kozian A, Licker M, Lin WQ, Maslow AD, Memtsoudis SG, Reis Miranda D, Moine P, Ng T, Paparella D, Ranieri VM, Scavonetto F, Schilling T, Selmo G, Severgnini P, Sprung J, Sundar S, Talmor D, Treschan T, Unzueta C, Weingarten TN, Wolthuis EK, Wrigge H, Amato MB, Costa EL, de Abreu MG, Pelosi P, Schultz MJ, Network Investigators PROVE (2016) Association between driving pressure and development of postoperative pulmonary complications in patients undergoing mechanical ventilation for general anaesthesia: a meta-analysis of individual patient data. Lancet Respir Med 4:272-280. https://doi.org/10.1016/S2213-2600(16)00057-6

13. Bugedo G, Retamal J, Bruhn A (2017) Driving pressure: a marker of severity, a safety limit, or a goal for mechanical ventilation? Crit Care 21:199. https://doi.org/10.1186/s13054-017-1779-x

14. Cressoni M, Gotti M, Chiurazzi C, Massari D, Algieri I, Amini M, Cammaroto A, Brioni M, Montaruli C, Nikolla K, Guanziroli M, Dondossola D, Gatti S, Valerio V, Vergani GL, Pugni P, Cadringher P, Gagliano N, Gattinoni L (2016) Mechanical power and development of ventilator-induced lung injury. Anesthesiology 124:1100-1108. https://doi.org/10.1097/ALN 0000000000001056

15. Gattinoni L, Tonetti T, Cressoni M, Cadringher P, Herrmann P, Moerer O, Protti A, Gotti M, Chiurazzi C, Carlesso E, Chiumello D, Quintel M (2016) Ventilator-related causes of lung injury: the mechanical power. Intensive Care Med 42: 1567-1575. https://doi.org/10.1007/s00134-016-4505-2

16. Serpa Neto A, Deliberato RO, Johnson AEW, Bos LD, Amorim P, Pereira SM, Cazati DC, Cordioli RL, Correa TD, Pollard TJ, Schettino GPP, Timenetsky KT, Celi LA, Pelosi P, Gama de Abreu M, MJ S, PROVE Network Investigators (2018) Mechanical power of ventilation is associated with mortality in critically ill patients: an analysis of patients in two observational cohorts. Intensive Care Med 44(11):1914-1922. https://doi.org/10.1007/s00134-018-5375-6

17. Zhang Z, Zheng B, Liu N, Ge H, Hong Y (2019) Mechanical power normalized to predicted body weight as a predictor of mortality in patients with acute respiratory distress syndrome. Intensive Care Med. 39:34-39. https://doi.org/10.1007/ s00134-019-05627-9

18. Klein Klouwenberg PM, Ong DS, Bos LD, de Beer FM, van Hooijdonk RT, Huson MA, Straat M, van Vught LA, Wieske L, Horn J, Schultz MJ, van der Poll T, Bonten MJ, Cremer OL (2013) Interobserver agreement of centers for disease control and prevention criteria for classifying infections in critically ill patients. Critical Care Medicine 41(10):2373-2378. https:// doi.org/10.1097/CCM.0b013e3182923712

19. van Vught LA, Klein Klouwenberg PM, Spitoni C, Scicluna BP, Wiewel MA, Horn J, Schultz MJ, Nürnberg P, Bonten MJ, Cremer OL, van der Poll T, MARS Consortium (2016) Incidence, risk factors, and attributable mortality of secondary infections in the intensive care unit after admission for sepsis. JAMA 315(14):1469-1479. https://doi.org/10.1001/jama. 2016.2691

20. Villar J, Fernández RL, Ambrós A et al (2015) A clinical classification of the acute respiratory distress syndrome for predicting outcome and guiding medical therapy*. Critical Care Med 43:346-353. https://doi.org/10.1097/CCM. 0000000000000703

21. Villar J, Blanco J, del Campo R et al (2015) Assessment of $\mathrm{PaO}(2) / \mathrm{FiO}(2)$ for stratification of patients with moderate and severe acute respiratory distress syndrome. BMJ Open 5:e006812. https://doi.org/10.1136/bmjopen-2014-006812

22. Bos LD, Schouten LR, Cremer OL, Ong DSY, Schultz MJ, MARS consortium (2016) External validation of the APPS, a new and simple outcome prediction score in patients with the acute respiratory distress syndrome. Ann Intensive Care 6:89. https://doi.org/10.1186/s13613-016-0190-0

23. Pisani L, Roozeman J, Simonis FD et al (2017) Risk stratification using SpO2/FiO2 and PEEP at initial ARDS diagnosis and after $24 \mathrm{~h}$ in patients with moderate or severe ARDS. Ann Intensive Care 7:108. https://doi.org/10.1186/s13613-017-03279

24. Chatburn RL, Volsko TA (2010) Documentation issues for mechanical ventilation in pressure-control modes. Respir Care 55:1705-1716

25. Gattinoni L, Marini JJ, Collino F, Maiolo G, Rapetti F, Tonetti T, Vasques F, Quintel M (2017) The future of mechanical ventilation: lessons from the present and the past. Crit Care 21:183. https://doi.org/10.1186/s13054-017-1750-x

\section{Publisher's Note}

Springer Nature remains neutral with regard to jurisdictional claims in published maps and institutional affiliations. 